\title{
Developmental Dental Anomalies of Primary and Permanent Dentition
}

\author{
Chaitanya P. Puranik* and Roopa P. Gandhi \\ Department of Pediatric Dentistry, University of Colorado, USA
}

*Corresponding author: Chaitanya P. Puranik, B.D.S., M.S., M.Dent.Sci., Ph.D., Assistant Professor and Director of Predoctoral Education, Department of Pediatric Dentistry, School of Dental Medicine, Children's Hospital Colorado, University of Colorado, 13123 East 16th Avenue, Box B240, Aurora, CO 80045, USA, Tel: (720) 777-2719; Fax: (720) 777-7238; Email: chaitanya.puranik@childrenscolorado.org

\section{Review Article}

Volume 4 Issue 4

Received Date: December 07, 2019

Published Date: December 23, 2019

DOI: 10.23880 /oajds- 16000241

\section{Abstract}

Development of the primary and permanent dentition is a highly regulated process in humans. A cascade of signaling pathways occur in a spatio-temporal manner resulting in the development and eruption of the human dentition. Any developmental aberrations in shape, size, number, and position can lead to deviations from normal development of teeth. This chapter discusses each developmental dental anomaly in both dentitions with special emphasis on causative factors at local, systemic, environmental or genetic levels. A review of findings, clinical implications and treatment options is provided for each anomaly. Dentists should be aware of these developmental dental anomalies due to the possible associations with systemic conditions or pathologies.

Keywords: Primary dentition; Permanent dentition; Tooth anomalies; Dental anomalies; Developmental disturbances

Abbreviations: HOX: Homeobox; SRA: Short Root Anomaly; MMP-9: Matrix Metalloproteinase; PAX9: Paired Box Gene 9; MSX1: Muscles Segment Homeobox 1; AXIN2: Axis Inhibition Protein 2; PFE: Primary Failure Of Eruption; PTH1R: Parathyroid Hormone Receptor 1; DDP: Distally Displaced Premolar; Wnt-1: Wingless Int-1; MSX1 And MSX-2: Msh Homeobox 1 And 2; TNF: Tumor Necrosis Factor; BMP: Bone Morphogenetic Protein; FGF: Fibroblast Growth Factor; AI: Amelogenesis Imperfect; AMBN: Ameloblastin; ENAM: Enamelin; DSPP: Dentin Sialophosprotein; TUFT1: Tuftelin; KLK4: Kllikrein4; MMP20: Matrix Metalloproteinase 20; CPP-ACP: Casein Phosphopeptide and Amorphous Calcium Phosphate;
MIH: Molar-Incisor Hypomineralization; DI: Dentinogenesis Imperfecta.

\section{Introduction}

Dental development (or odontogenesis) is a highly regulated process that is driven by a cascade of epithelialmesenchymal interactions involving the oral ectoderm and cranial neural crest derived ectomesenchyme [1]. Beginning in the embryonic and fetal stages of human development, the formation of teeth continues until adulthood. Odontogenesis is characterized by several sequential stages such as tooth initiation, morphogenesis, 
cytodifferentiation, mineralization, and bone remodeling (during tooth eruption) [2]. Developmental dental anomalies of the primary and permanent dentition occur when specific disturbances in one or more stages of odontogenesis occur during human development [3]. Such anomalies are morphologically diverse and can be characterized as those affecting shape, number, position, and the enamel or dentin structures.

The etiology of dental developmental anomalies (or defects) is complex and can involve multiple causative agents such as local factors (e.g., trauma), genetic influences, or environmental insults (e.g., alcohol or drug exposures during the fetal period, febrile illnesses). From the genetic standpoint, the process of odontogenesis is primarily under the control of the homeobox (HOX) genes (e.g., MSX1, MSX2, SHH, PAX9) which play critical roles in multiple stages of tooth development [4]. Aberrations in tooth development have been associated with a number of genetic mutations affecting these regulatory molecules, however there are still unidentified genes requiring further investigation [5]. Notably, the genetic causation of tooth anomalies can be readily recognized in patients for whom certain systemic conditions or syndromes result in specific abnormalities of the primary or permanent teeth.

In this review article, the dental developmental anomalies affecting the shape, number, position, and enamel or dentin structures of primary and permanent dentition will be discussed. The etiology, prevalence, pertinent clinical and radiographic features, associated systemic conditions or syndromes, and an overview of management for these anomalies are also provided to prepare the clinician to recognize, educate, and appropriately treat affected patients.

\section{Developmental Anomalies}

\section{Shape Anomalies}

Microdontia: Microdontia is the term used to describe teeth that appear to be smaller than the normally expected variations in tooth size. The etiology of microdontia is related to disturbances in the process of odontogenesis and is also associated with familial inheritance patterns, reflecting a genetic basis for the anomaly. In other instances, isolated and spontaneous cases can occur with no identified cause.

The teeth most frequently affected by microdontia in decreasing order are the maxillary lateral incisors, (Figure 1), third molars, and supernumerary teeth. This condition can be isolated to a single tooth or group of teeth (localized) or involve all teeth (generalized) [6]. In localized microdontia, the affected tooth may not only appear smaller in size but also present with an altered shape. This clinical presentation most commonly occurs with the maxillary lateral incisors, where the tooth crown appears cone or peg shaped. The prevalence of pegshaped maxillary permanent lateral incisors has been reported to be $1.8 \%$ [7] with a greater predominance in women compared to men, and a more common occurrence in patients with Down syndrome (Figure 1) and orofacial clefting (presenting on the side of the cleft) [8].

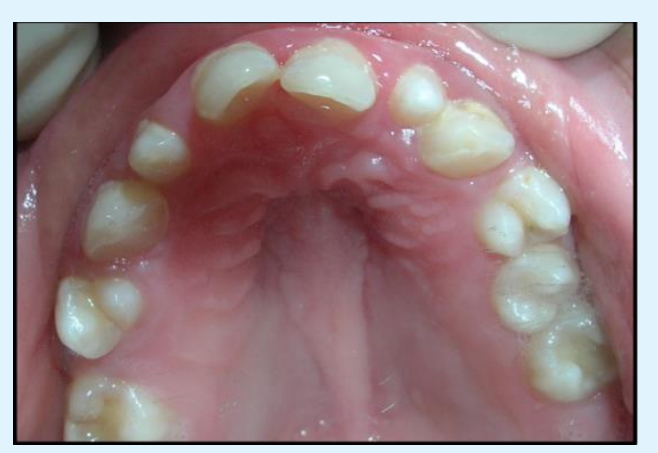

Figure 1: Clinical photograph showing microdontia of maxillary permanent lateral incisor in a patient with Down syndrome.

Where microdontia affects all teeth, it may be classified as true generalized microdontia (all affected dentition appear smaller than normal) or relative or pseudo generalized microdontia (affected dentition appears smaller than normal due to the abnormally enlarged size of the maxilla or mandible) [6]. True generalized microdontia is rare and has been reported in pediatric patients receiving radiotherapy or chemotherapy treatment during tooth development [9], and in patients suffering from pituitary dwarfism [10].

Other conditions associated with isolated and generalized microdontia include Down syndrome, Hallerman-Streiff syndrome and Williams [11] syndrome [11-13]. Microdontia can also be strongly associated with other dental developmental anomalies such as hypodontia. Based on the severity of the condition, management of microdontia can be conservative (esthetic or restorative treatment) or a long-term comprehensive interdisciplinary approach involving restorative, orthodontic, surgical, and prosthetic treatments to create a more normal shape of the affected tooth, thereby improving the overall esthetics [14]. 
Macrodontia: Macrodontia, also known as megadontia or megalodontia, occurs when a single tooth or group of teeth present with a larger than normally expected size. The etiology of macrodontia is still unknown. Similar to microdontia, the classification of macrodontia includes localized or isolated (single tooth or groups of teeth), true generalized (all teeth are larger than normal), and relative or pseudo generalized (all teeth are either normal or slightly larger than relatively smaller jaws). Isolated macrodontia is a rare condition and occurs more frequently in permanent incisors, canines, and mandibular third molars. Macrodontia involving isolated groups of teeth presents unilaterally in hemifacial hypertrophy, with teeth on the affected side appearing abnormally larger than the unaffected side.

Generalized macrodontia, is also a rare condition that is seen in pituitary gigantism. Other associated systemic conditions associated with macrodontia include insulinresistant diabetes, Oto-dental syndrome, KBG syndrome, and XYY syndrome [15-17]. The overall reported prevalence of macrodontia affecting permanent teeth is $0.03-1.9 \%$ with a higher occurrence in males [18-20].

When erupted, the clinically enlarged crown size of a macrodont tooth is apparent but may have a distorted morphology that can resemble gemination or fusion. In other instances, the clinical finding of an unerupted tooth can lead the dentist to take the appropriate radiograph to detect an unerupted macrodont, requiring further interventions that may include extractions of primary teeth to aid eruption. The treatment options are dependent on the size and shape of the affected tooth or teeth and the related functional or esthetic concerns. Complex endodontic, surgical, and restorative procedures may be performed to restore esthetics and function. In other cases, definitive extraction of the affected tooth may be planned.

Taurodontism: Taurodontism is a shape anomaly that occurs due to a failure of appropriate invagination of Hertwig's epithelial root sheath. This results in the characteristic features of the anomaly - an enlarged pulp chamber, apical displacement of the pulpal floor, and lack of constriction at the cemento-enamel junction. The term "taurodontism" (bull tooth) comes from the Latin term "tauros" which means "bull" and the Greek word "odus" which means "tooth" [21].

Taurodontism can be classified into three types in order of increasing severity: (a) hypotaurodontism, (b) mesotaurodontism, and (c) hypertaurodontism [22]. In the mild form (hypotaurodontism), only the pulp chamber is enlarged, whereas in the most severe form (hypertaurodontism), the root furcation occurs in close proximity to the root apices due to the disproportionately enlarged crown and pulp chamber relative to the roots of the affected tooth.

Taurodontism is detected by radiographic evaluation since the affected teeth generally present with a clinically normal morphological appearance of the crown (Figure 2). The radiographic features include a tapered rectangular appearance of the tooth (tapering towards the roots), the enlarged appearance of the pulp chamber, and the apical displacement of the root furcation.

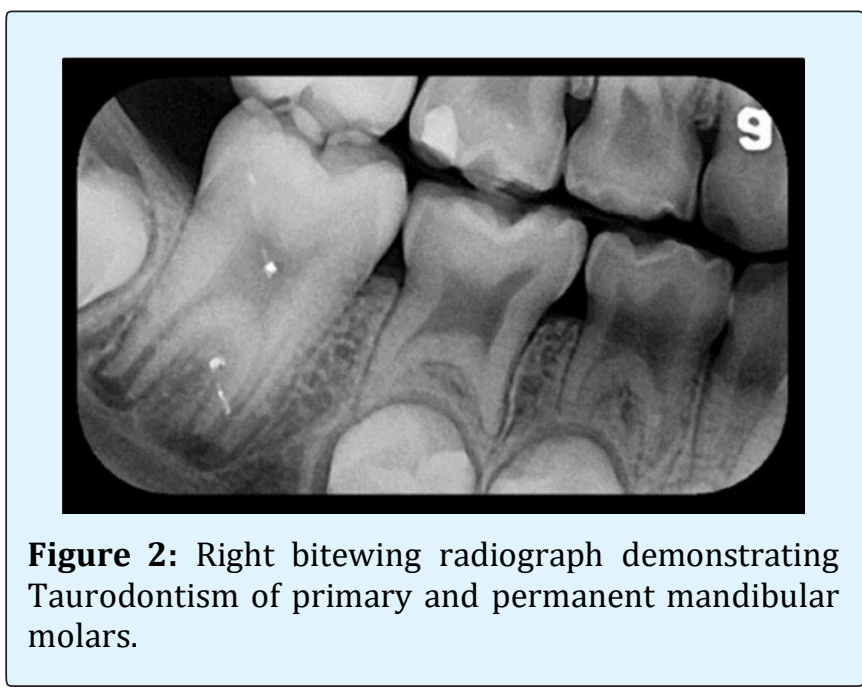

The prevalence rate of taurodontism affecting permanent dentition has been estimated to range from $2.5 \%$ to $11.5 \%$ with no apparent gender predilection [23]. Taurodontism can present as an isolated condition or in conjunction with other developmental conditions or syndromes including Klinefelter syndrome, Tricho-DentoOsseous syndrome, Down syndrome, Van der Woude syndrome, and hypophosphatasia [23].

Clinical complications associated with taurodontism include the greater risk for pulpal exposure due to the enlarged pulp chamber, if the tooth is affected by dental caries or during a dental procedure. Where endodontic therapy is required, it can pose a significant challenge to the endodontist and may require a modified filling technique for adequate obturation [24]. Taurodontism can sometimes present problems with prosthodontic treatment (post-core) or extractions. 
Short Root Anomaly: Short root anomaly (SRA), first described by Lind, is a shape anomaly affecting root development that is characterized by reduced crown to root ratios and short roots that have rounded apices [25]. This disorder most commonly affects the maxillary incisors, followed by maxillary and mandibular premolars, with a bilateral presentation [26]. It has been reported to have an autosomal dominant pattern of inheritance reflecting a genetic basis for the disorder [27].

The prevalence of SRA ranges from $2.4-2.7 \%$ in Caucasian populations and there is a higher reported prevalence in Hispanic (Figure 3) [26] and Mongolian populations of up to $10 \%$ [27-29]. SRA often occurs with other developmental dental anomalies such as hypodontia, supernumerary teeth, microdontia, dens invaginatus, taurodontism, and obliterated pulp chamber $[27,30,31]$.

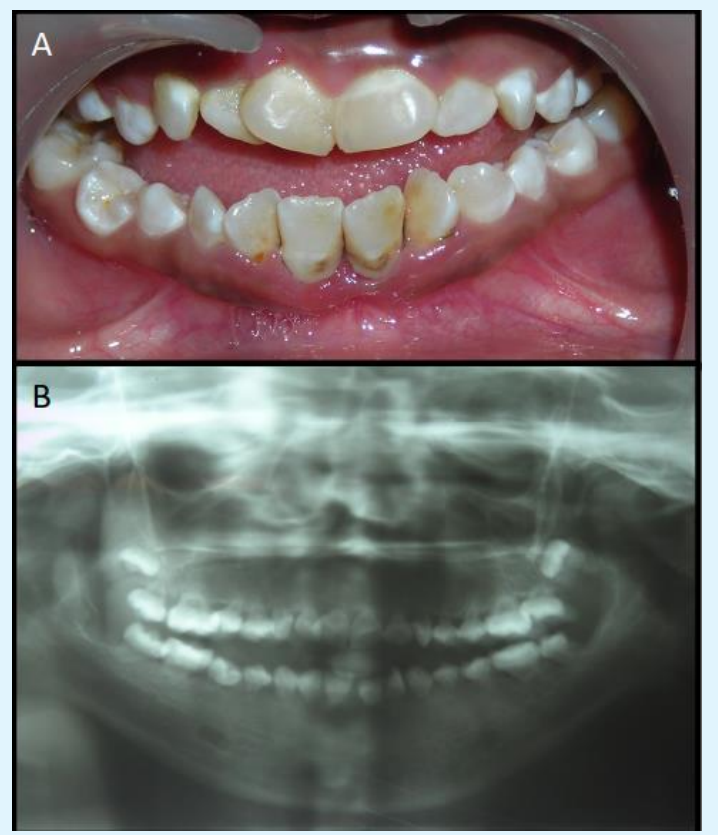

Figure 3: Clinical photograph (A) and panoramic radiograph (B) of a generalized non-syndromic short root anomaly in a 15-year-old patient.

Typically, no treatment is needed in mild or localized cases. However, clinicians should be aware that patients with SRA have an increased risk of root resorption during orthodontic treatment [32]. The pathogenesis for root resorption associated with SRA has been linked to the altered levels of collagenases such as matrix metalloproteinase (MMP-9) detected in the gingival crevicular fluids of affected patients [33]. Since collagenase activity (e.g., MMP-9) plays a critical role in periodontal remodeling during orthodontic treatment, such alterations can result in early tooth loss when occurring with severely reduced crown to root ratios. In severe cases, when the crown: root ratio is severely compromised, a periodontal splinting of affected group of teeth may be warranted.

\section{Number Anomalies}

\section{Hypodontia}

Hypodontia is a dental anomaly in which there is an absence of $\leq 6$ teeth excluding third molars. It is the most common dental anomaly and is present in about $1 / 5$ th of the population. The prevalence of hypodontia is variable in different populations [34]. Females are more commonly affected than males. However, there are studies demonstrating that it is more common in males [35]. The prevalence of hypodontia in the primary dentition in Caucasian populations is $<1 \%$. Primary maxillary incisors and mandibular central incisors are both commonly affected with hypodontia [36]. Agenesis of primary teeth often leads to agenesis of the permanent successor. Prevalence of hypodontia during permanent dentition stages is more common. The most common missing teeth during permanent hypodontia are mandibular second premolar and lateral incisors [37]. Hypodontia in permanent dentition stages can be present even when a full complement of primary teeth are present.

Bilateral agenesis of teeth is more common than unilateral [37]. Hypodontia can be present as nonsyndromic or syndromic in association with Down syndrome, Ectodermal dysplasia, Pierre-robin sequence, Van der Woude syndrome and cleft lip and palate. Hypodontia can lead to ectopic eruption of adjacent teeth and spacings between teeth along with dental rotations. Etiology of hypodontia includes possible agenesis of tooth buds. Specific areas in dental lamina maybe susceptible to polygenetic and environmental effects thereby leading to hypodontia. More than 300 genes are involved in dental morphogenesis. However, paired box gene 9 (PAX9), muscles segment homeobox 1 (MSX1) and axis inhibition protein 2 (AXIN2) are commonly reported to be associated with hypodontia [36]. Hypodontia can lead to esthetic concerns due to missing teeth and have negative psycho-social sequelae.

Prosthetic rehabilitation including restoration of missing teeth is recommended. Depending on the age of 
patient, space available and future aesthetic needs treatment planning can be staggered to involve transient treatment including a resin-supported bridge (Carolina bridge) or a Maryland bridge (Figure 4). Future permanent restorative options involving implantsupported crowns can be planned based on the age of the patient. Depending on the skeletal or orthodontic findings, space closure or canine substitutions for missing lateral incisors has been employed in the past [36].

\section{Oligodontia}

Oligodontia is a dental anomaly in which there is an absence of $>6$ teeth excluding 3rd molars [36]. Oligodontia can be present in non-syndromic or in association with syndromes such as Ectodermal dysplasia, Orofacial digital syndrome, Witkop-tooth-nail syndrome, Van der Woude syndrome, Down syndrome, Klinefelter syndrome, Ellis van Creveld syndrome, Rieger syndrome, Incontinent Pigmenti [38], or Emanuel syndrome [39].

Comprehensive prosthetic management to replace missing teeth is recommended in non-syndromic cases. Oligodontia with syndromic association in young patients may pose some challenges due to uncooperative patient behavior and additional systemic findings [39].

\section{Anodontia}

Anodontia is a rare dental anomaly in which there is absence of all teeth. It is commonly associated with syndromes such as Witkop's tooth-nail syndrome Rieger syndrome, Holoprosencephaly, Kabuki syndrome, WolfHirschhorn syndrome and Hair-nail-teeth dysplasia [36]. Depending on the age, cooperation, and syndromic or systemic findings, prosthetic rehabilitation can be done using an implant supported complete denture.

\section{Hyperdontia}

Hyperdontia is defined as the presence of a tooth or teeth in addition to the full complement of permanent or primary teeth. The erupted or unerupted additional tooth is termed as a supernumerary tooth. Hyperdontia can be present unilaterally or bilaterally. Supernumerary teeth are most commonly noted in the anterior region of the maxilla. The prevalence of hyperdontia in the permanent dentition is approximately $2 \%$ [40]. Localized hyperactivation of dental lamina is considered as possible etiologic basis for development of hyperdontia [41]. Supernumerary tooth/teeth can be classified based on the number of extra teeth, shape, size, site and laterality [42] (Figure 4).
In addition to dental lamina hyperactivation theory, possible theories of etiology of hyperdontia are atavism theory, dichotomy theory, and theory of epithelial remnant of dental lamina [43]. Atavism theory states that phylogenetic reversion in humans to primates (3 pairs of incisors) can lead to development of supernumerary teeth. Dichotomy theory states that single tooth bud splits into 2 equal (twin) or unequal (rudimentary) parts which can lead to formation of a supernumerary tooth or teeth. Epithelial remnants of dental lamina as a plausible underlying factor for the development of hyperdontia is the most commonly accepted theory [44].

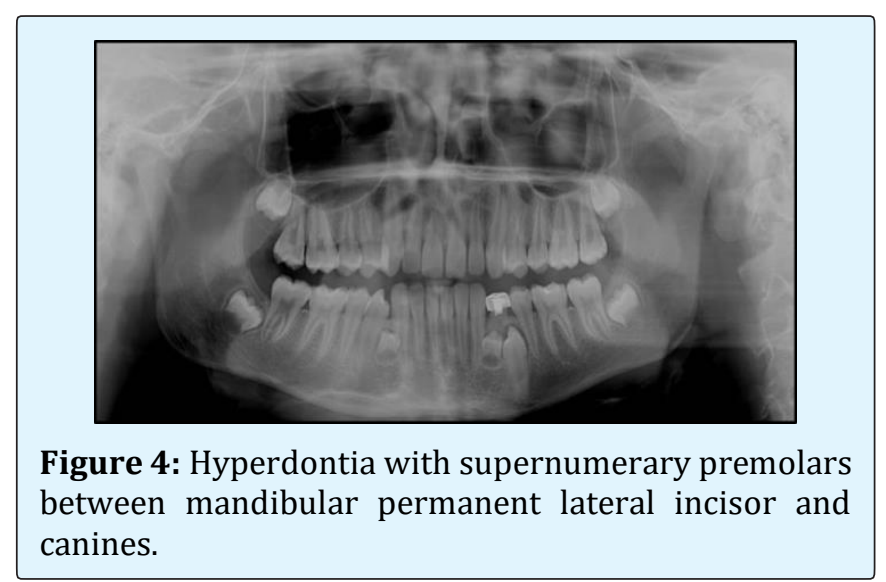

Hyperdontia is clinically diagnosed by the presence of erupted or unerupted supernumerary teeth detected during clinical or radiographic examination (Figure 4). There is no clear guideline or consensus regarding the treatment of supernumerary teeth [45]. Supernumerary teeth can clinically lead to crowding, displacement or root resorption of erupted teeth. Additional problems associated with supernumerary teeth includes possible development of pathology (cysts). Hyperdontia can be present non-syndromically or in association with various syndromes including Cleidocranial dysplasia, Gardner's syndrome, Enamel-renal-gingival syndrome, Crouzon's syndrome, Ehlers-Danlos syndrome, Hallerman-Streiff syndrome, Incontinentia Pigmenti, Noonan syndrome, Robinow syndrome [46]. Sequence similarly family FAM10a mutation has been associated with supernumerary premolars [47].

If no pathology or other orthodontic problems are noted with the supernumerary tooth then immediate extraction is not warranted [48]. Some clinicians have recommended immediate extraction of supernumerary tooth [49]. Figure 5 demonstrates a clinical decisionmaking tree based on the information provided by Amarlal, et al. regarding management of hyperdontia [50]. 


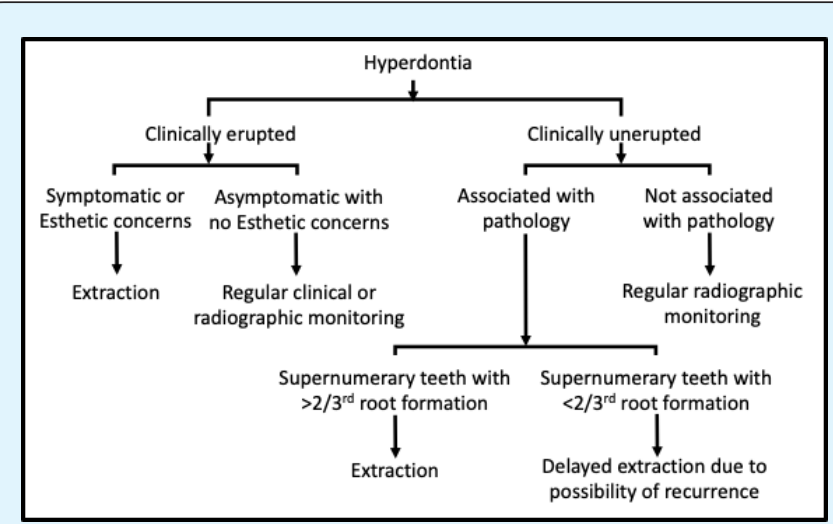

Figure 5: A clinical decision-making tree for management of hyperdontia.

\section{Mesiodens}

Mesiodens refers to a supernumerary tooth located in the maxillary arch between two central incisors. When it is occurs in the primary dentition, it is referred to as supplementary mesiodens [44]. In the permanent dentition, the term used is rudimentary mesiodens. The prevalence of this anomaly is $<2 \%$ [51] and is more common in males in comparison to females [52]. It can be associated with craniofacial syndromes such as Gardner's syndrome, Cleido-cranial dysostosis, and cleft lip and palate or occur in an isolated manner. A possible genetic basis has been postulated as siblings of patients diagnosed with mesiodens have also demonstrated this condition [51].

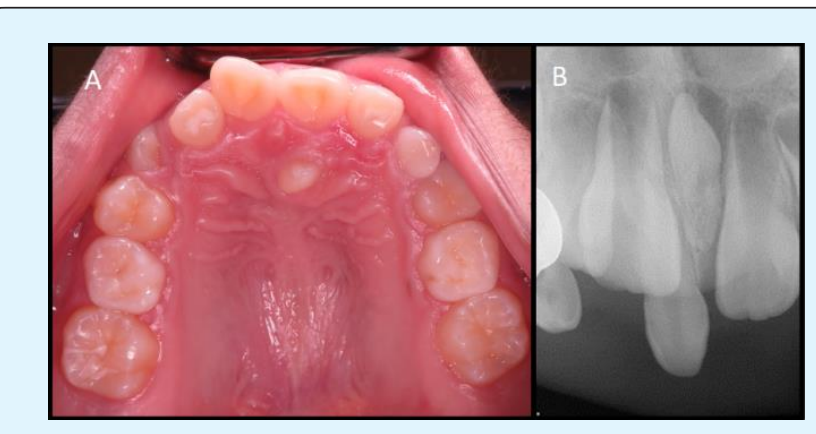

Figure 6: Clinical photograph of a mesiodens in an 11year-old patient on the mid-palatal area (A), periapical radiographs of another 7 -year-old patient showing two mesiodens (one erupted and one unerupted) between permanent central incisors.

Clinical features of a mesiodens can depend on the involved dentition (primary or permanent). Supplementary mesiodens may appear as a natural tooth.
Rudimentary mesiodens can exhibit abnormal size or shape [44] and more commonly with a conical or peg shape [52]. Mesiodens of the primary or permanent dentition can erupt into the oral cavity displacing central incisors. These erupted teeth are easy to detect clinically whereas an inverted, unerupted mesiodens can only be detected on an occlusal radiograph (Figure 6). In case of unerupted mesiodens, radiographic evaluation is indicated with multiple projections (cone shift) to identify the facial or palatal position of a mesiodens.

In approximately $25 \%$ of cases, a mesiodens will be expected to erupt, making radiographic evaluation a fundamental component of initial diagnosis, especially if there are suspicious clinical features including delayed eruption or diastema of the central incisors [53]. It has been reported that mesiodens can delay or prevent eruption of central incisors in approximately $50 \%$ of the cases. Abnormal positioning of the central incisor can be detected in more than $75 \%$ of cases. Rare complications associated with mesiodens include dilaceration of the central incisor root, cystic transformation or eruption into the nasal cavity [44].

Treatment for an erupted mesiodens includes extraction followed by interceptive orthodontics to close the spacing between central incisors. Surgical extraction of un-erupted mesiodens in primary dentition is also an option. However, the risk of damage to the developing permanent incisor is high. Delayed surgical extraction of mesiodens is preferred until at least 10 years of age when it is anticipated that the apices of the permanent central incisors are closed. Minor-moderate spacing is common with mesiodens and diastema closure can be considered after surgical extraction [52].

\section{Positional Anomalies}

\section{Ankylosis}

Ankylosis is defined as the fusion of the root (dentin or cementum) of a tooth to bone [54]. This may lead to the discontinued eruption of the tooth. In some cases, traumatic dental injuries have been reported as a cause of ankylosis. However, in many instances the cause for ankylosis is unknown. The prevalence of ankylosis of the primary molars is reported to be 8 to $14 \%$ [54]. Primary mandibular second molars are more commonly affected than any other primary teeth [55].

In primary or permanent dentition, the most common clinical presentation of ankylosis is a "submerged" tooth that appears to be in infra-occlusion compared to the 
adjacent teeth [55]. A dull sound on vertical percussion is a characteristic of an ankylosed tooth. Submergence of the ankylosed tooth occurs due to the continued vertical eruption of adjacent teeth in the alveolar bone while the affected tooth fails to do the same. Additional findings associated with ankylosed teeth are supraeruption of opposing the tooth and collapse of the dental arch due to tipping of adjacent teeth towards the ankylosed tooth. In some cases, the successor teeth (e.g., premolars) tends to erupt ectopically by tipping distally [54].

The exfoliation of ankylosed primary molars typically follows the normal exfoliation schedule with a normal resorption pattern that warrants no further treatment. However, when evidence of tipping of adjacent teeth or supra-eruption of opposing primary teeth are noted, then definitive restorations such as stainless-steel crowns (Figure 7) or a composite build-ups can be planned to restore the occlusal plane [56]. When ectopic eruption of the succedaneous, premolar, is noted then extraction of ankylosed primary molar should be considered [54]. When ankylosis of permanent teeth is noted at a young age with esthetic needs, decoronation and root submergence (removal of clinical crown while leaving the radicular portion of the tooth) can be performed to preserve the alveolar bone for future implant placement with temporary restorative treatment [57]. Treatment of ankylosed permanent teeth can range from monitoring to advanced restorative treatment depending on the severity of the problem. When ankylosed teeth are planned for extraction due to poor prognosis, then a referral to an oral and maxillofacial surgeon may be necessary.

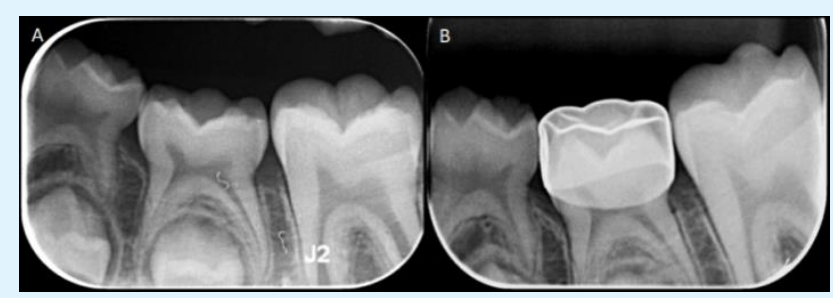

Figure 7: Periapical radiographs showing ankylosis of mandibular left second primary molar (submerged) with mesial tipping of permanent mandibular molar and distal tipping of first primary molar (A), restoration with stainless-steel crown to prevent reduction in arch length (B).

\section{Primary Failure of Eruption}

Normal dental eruption is characterized by three basic processes: (1) formation of osteoclasts to resorb bone (and facilitate eruption of a tooth through bone); (2) gingival resorption; and (3) elongation of the root. Primary failure of eruption (PFE) occurs when teeth fail to erupt despite a clear eruptive path. This is a rare disorder with a reported prevalence of $<1 \%$ [58]. PFE is associated with parathyroid hormone receptor 1 (PTH1R) mutation [59] and the effect of PTH1R mutation on the clinical manifestation of PFE is poorly understood [60].

Clinical manifestations include unilateral or bilateral posterior open bite with affected teeth presenting with partial or complete failure of eruption. Radiographically, teeth with complete loss of eruption will have a clear path for eruption and still clinically fail to erupt (Figure 8) [60]. Posterior teeth are more commonly affected than anterior teeth with an equal predisposition for primary and permanent teeth [61].

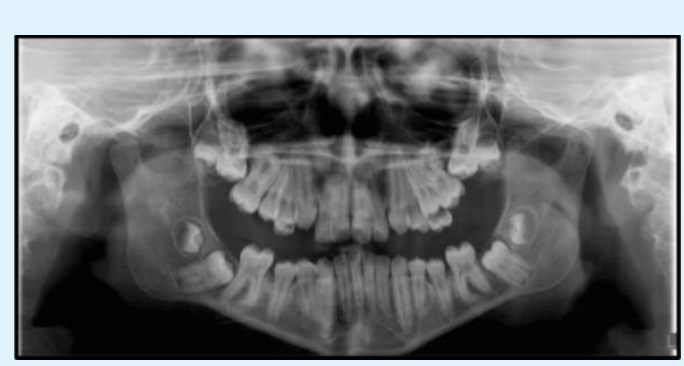

Figure 8: Primary failure of eruption of mandibular second molars in a 16- year-old patient.

After the diagnosis of PFE is confirmed no treatment should be instituted. Past treatment approaches such as surgical exposure of affected teeth and orthodontic traction are not recommended and may be associated with ankylosis of the affected tooth and untoward effects on adjacent teeth [60]. If the first permanent molar is involved, extraction should be planned to allow mesial drifting of the second permanent molar. However, if the second permanent molar is similarly affected, then it undermines a conservative extraction plan [62].

\section{Distally Displaced Premolars}

Second premolars can sometimes erupt ectopically with distal displacement and inclination towards the first permanent molar. Premolars with such findings are termed as distally displaced premolars (DDP). The clinical implications of DDP can include delayed exfoliation of the predecessor primary tooth and in severe circumstances, resorption of the first permanent molar.

Clinically, the finding associated with DDP includes delayed eruption of the second premolar and an over- 
retained second primary molar. Radiographically, this can be detected on a routine panoramic or periapical radiograph (Figure 9) where the vertical axis of the premolar crown appears distally tipped relative to the lower border of the mandible. Mild cases are usually selfcorrecting while a severe presentation requires extraction of the primary molar alone or in combination with surgical exposure and orthodontic extrusion and/or uprighting [63].

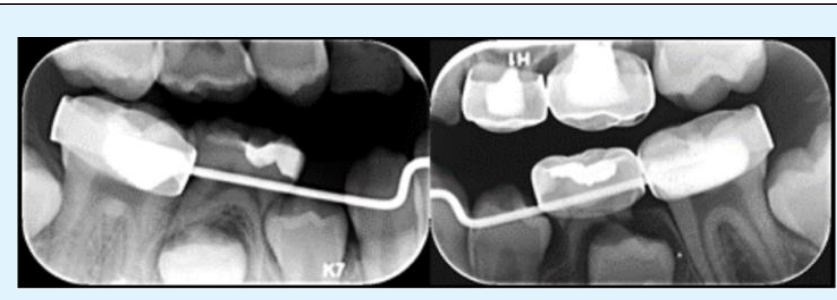

Figure 9: Bitewing radiographs showing distally displaced second premolars.

\section{Ectopic eruption}

Ectopic eruption is defined as the eruption of a tooth into a position other than normally expected in the arch. Such atypical eruption is more common with maxillary first permanent molars with an incidence of 2-6\% [64]. The etiology of this condition is not clear. However, local factors such as the steep mesial angulation of molars during eruption and the blocking of erupting teeth by the distal portion of primary second molars have been documented in some cases [65]. Ectopic eruption can run in families and hence, some genetic association has been speculated. Ectopic eruption of teeth is more common in patients with cleft lip or palate. Maxillary molars are more commonly affected than mandibular molars and there is no significant gender predisposition [66].

Clinical findings associated with ectopic eruption include the lack of visualization of the mesial marginal ridge in a partially erupted first permanent molar. In some cases, there may be supra-eruption of the distal part of the affected tooth resulting in a less than desirable contact position with the opposing molar or alveolar ridge. Radiographically, the long axis of the affected tooth is steeply inclined mesially and locked under the distal surface of the primary second molars. Resorption of the primary second molar root and reduction of arch length can be seen in cases with ectopic eruption of permanent first molars [65].

Approximately 3 out of 4 first permanent molars affected ectopic eruption will self-correct [66]. Therefore, no treatment is needed except for monitoring. Permanent first molars are usually monitored until 7 years of age. The likelihood of self-correction is reduced after 7 years or when resorption of the roots of primary second molars is noted [66]. Factors that need to be considered for treatment of ectopically erupting first permanent molars include: age of the patient, presence of premolars, status of the primary second molar, and severity of ectopic eruption [65]. The use of elastic separators between the primary second molar and ectopically erupting first permanent molar is usually the first line of treatment. Some clinicians use brass wires to create a separation between the primary second molar and to upright ectopically erupting first permanent molars (Figures $10 \mathrm{~A}$ and B). In severe cases when the ectopically erupting first permanent molar is physically locked under the distal aspect of second primary molar, a Halterman appliance may be the treatment of choice. The Halterman appliance derives anchorage from a clinically erupted tooth and uprights the ectopic molar using elastic chains stretched from a stainless-steel button (bonded on to the occlusal table of the ectopically erupting molar) to a wire looped distal to the ectopically erupting molar (Figure $10 \mathrm{C}$ and D). In cases of significant resorption of primary second molar roots, extraction may be necessary along with distalization of the ectopically erupting permanent first molar.

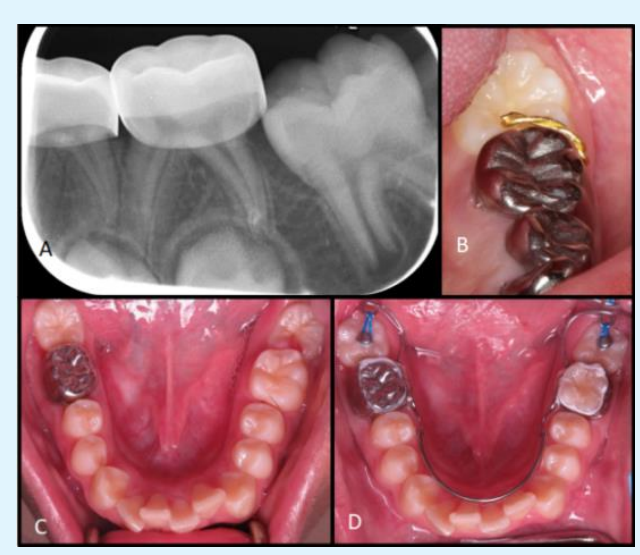

Figure 10: Periapical radiographs demonstrating ectopically erupting mandibular left first permanent molar due to uncrimped distal margin of stainlesssteel crown on second primary molar (A) and clinical photograph showing use of brass wire to upright (unlock) ectopically erupting first permanent molar (B). Clinical Photographs of ectopically erupting mandibular second permanent molars (C) after placement of a bilateral Halterman's appliance for uprighting of second molars (D). 


\section{Impaction}

Impaction is defined as the inability of a tooth to erupt into the oral cavity. Females are most commonly affected than males. Associated systemic factors include hypothyroidism, radiation therapy, Cleidocranial dysostosis and Amelogenesis imperfecta. Local factors include failure of the deciduous tooth to resorb, an abnormal eruptive path, presence of supernumerary teeth, crowding, trauma, and pathology.

The prevalence of third molar impaction ranges from 16-68\% [67] and females are more commonly affected than males. Untreated and impacted third molars have the potential for cystic transformation leading to possible pathology such as a dentigerous cyst, unicystic ameloblastoma, odontogenic keratocyst, and calcifying epithelial odontogenic tumor [68].

Canine impaction is defined as the intra-osseous position of a canine after the normal eruption time [69]. The most common tooth to be impacted is the maxillary permanent canine and the associated prevalence is reported to range from 0.2 to $2.4 \%$ depending on the population [70]. Various etiologic factors proposed for canine impaction include local hard tissue barriers, pathology, abnormal positioning of the incisors, and hereditary factors [70]. It is controversial as to whether non-resorption of a primary canine leads to an impacted permanent canine or if impaction of the permanent canine results in a non-resorbing primary canine. Facially impaction of a canine is more common than palatal impaction. In $82 \%$ of cases with dental crowding, facially impacted canines are noted as compared to $18 \%$ cases with dental crowding along with palatal impaction of a permanent canine [69].

Clinically, in cases with canine impaction the normal facial prominence of the canine is absent. Palatally impacted canines may demonstrate a clinically detectable palatal prominence or bulge. An impacted canine is usually detected at or after 8 years of age on a routine panoramic radiograph. An excessive mesial inclination of the developing permanent canine is a typical finding associated with possible future impaction. It is difficult to determine whether the impaction is buccal or palatal from a panoramic radiograph and advanced radiographic techniques such as CBCT may be needed. An alternative, less expensive, and less invasive radiographic approach is to consider taking two periapical radiographs using Clarke's rule (cone shift) to aid in the determination of the position of an impacted canine.

Chaitanya P. Puranik and Roopa P. Gandhi. Developmental Dental Anomalies of Primary and Permanent Dentition. J Dental Sci 2019, 4(4): 000241.
An ectopically erupting permanent canine can possibly lead to pathologic resorption of roots of the lateral incisor and hence identifying and treating ectopic eruption of canines during the mixed dentition stage is critical (Figure 11). Based on the panoramic evaluation, if the crown of the developing permanent canine appears to overlap the root of the permanent lateral incisor then extraction of the primary canine teeth is recommended [71,72]. Extraction of the primary canine allows eruption of the impacted permanent canine in about $62 \%$ cases and a favorable canine position in $17 \%$ of cases. However, extraction of primary canine does not guarantee resolution of permanent canine impaction [73]. Surgical exposure in combination with orthodontic traction of the permanent canine [74] may also be considered following primary canine extractions. Even after surgical repositioning, there may be instances when root torque of the affected permanent canine is not optimal.

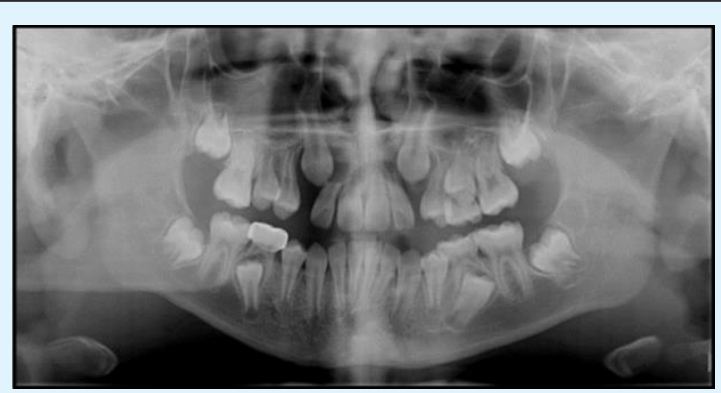

Figure 11: Panoramic radiograph demonstrating impaction of both maxillary canine and resorption of permanent maxillary lateral incisor roots. Distally displaced mandibular second premolars can also be noted on the radiograph.

Complications associated with unerupted permanent canines include the risk for infection and cystic follicular lesions. Some studies have demonstrated development of calcifying epithelial odontogenic cysts and adenomatoid odontogenic tumors [68]. Additionally, impacted or mesially inclined canines can lead to possible root resorption of the adjacent permanent lateral incisor rootss (Figure 11) [73]. The risk for development of pathology underlines the importance of continued monitoring of impacted canines as well as early intervention whenever possible.

\section{Anomalies of Infancy and Childhood}

\section{Natal and Neonatal Teeth}

Natal and neonatal teeth are rare developmental anomalies that occur during the newborn period. Natal 


\section{Open Access Journal of Dental Sciences}

teeth are defined as those teeth that are present at birth, whereas neonatal teeth erupt during the neonatal period (first 30 days of life) [75]. Additionally, "early infancy teeth", have been reported in the literature and these erupt between 1 - 3.5 months of age [76]. Other synonymous terms for prematurely erupted primary teeth are 'congenital teeth', 'fetal teeth' or 'dentitia praecox'.

Several causative factors for natal and neonatal teeth have been proposed including autosomal dominant inheritance, superficially positioned tooth germs, accelerated eruptions due to hormonal stimulation or febrile illnesses, and environmental toxins [77-81]. Natal and neonatal teeth have been shown to occur with certain systemic conditions such as Hallerman-Streiff syndrome, Pfeiffer syndrome, orofacial clefting, and epidermolysis bullosa [82].

The reported prevalence of natal and neonatal teeth varies widely with ranges from $1: 1000$ to $1: 30,000$ and natal teeth occurring more frequently than neonatal teeth [83]. The mandibular incisor region is the most common location of presentation. It has been found that in the majority of cases, natal and neonatal teeth are primary teeth and in the remaining instances, can be present as supernumerary teeth. There is currently no established gender predilection, although some authors suggest a greater proportion of affected females compared to males [75].

The clinical presentation of natal/neonatal teeth can be classified as mature or immature [76]. In mature cases, the tooth has typical development of the crown and root as well as a normal appearance of the enamel. In the cases of immature natal/neonatal tooth, there may be alterations in size (smaller), shape (e.g., conical), hypoplastic appearance of the enamel (yellowish-white appearance) and underdeveloped or total failure of the roots (increasing tooth mobility).

Several complications result from natal and neonatal teeth including feeding difficulties with lack of weight gain or failure to thrive, Riga-Fede disease (ulceration of the ventral tongue, Figure 12), nipple pain or ulceration (in the feeding mother), and hypermobility of the affected tooth [84]. Treatments can include smoothing of the sharp surfaces, placement of a composite resin, or extraction of the natal/neonatal tooth to improve feeding related concerns during the newborn period $[85,86]$.

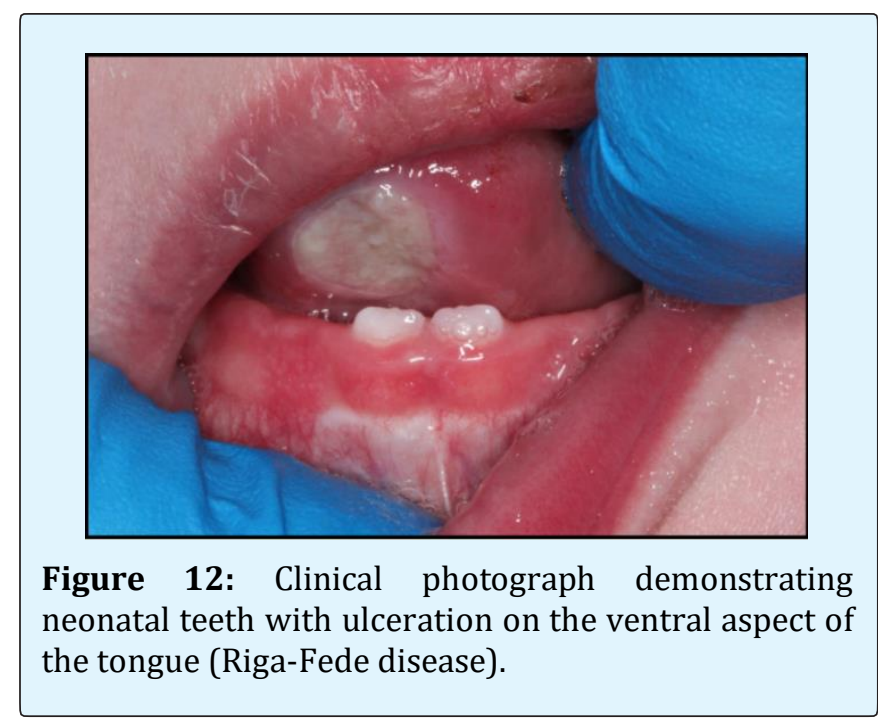

\section{Fusion}

Fusion is characterized by the union between enamel and dentin of two or more independently developing primary or permanent teeth. Theories regarding the etiology of the fused teeth include that this phenomenon arises due to mechanical pressure that adjacent teeth follicles apply upon each other, racial determinants, and hereditary conditions [87].

The clinical and radiographic presentation of fusion can be complete (total or true fusion or incomplete (partial or late fusion) and this is dependent on the stage of tooth development during which this phenomenon occurs. For example, if two tooth buds experience fusion before their respective calcification stages, full fusion results, and presents clinically as a single large crown [88]. In contrast, if fusion of the two buds occurs during the advanced morpho-differentiation stage of tooth development, the clinical appearance would present as fused teeth that have two separate crowns delineated by a groove. Radiographically, these teeth would present with two separate pulp chambers and root canals and the fusion will be limited to the roots of these teeth [89]. Fusion more commonly occurs unilaterally in the primary rather than in permanent dentition, and most often in the anterior region with involvement of the mandibular lateral incisors and canines (Figure 13) [90].

Fusion of primary teeth has been found to be associated with developmental anomalies of the permanent dentition in several studies. Such anomalies 
can occur in regions that are unrelated to the site of the fused teeth or at the site of fusion. Anomalies of the permanent dentition reported at the site of primary fused teeth include peg-shaped incisors, occurrence of fusion of the successors, and supernumerary or congenitally missing successors [90,91]. Unrelated tooth anomalies that have been reported include hypodontia, talon cusps, delayed eruption, and ectopic eruption [90].

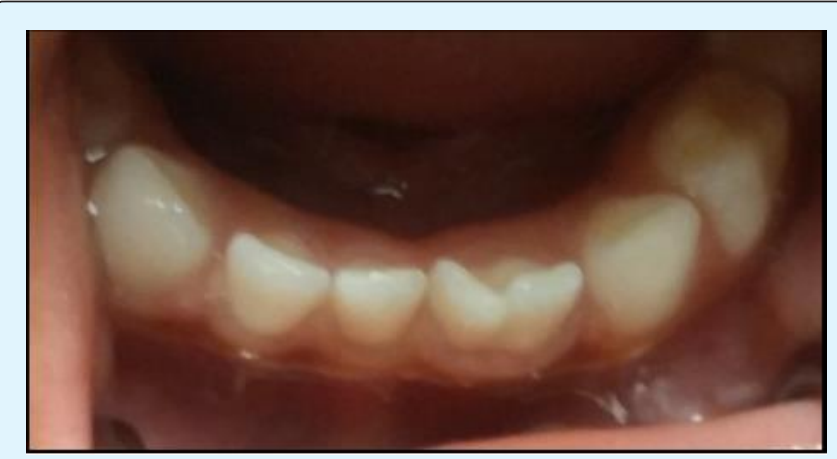

Figure 13: Clinical photograph showing fusion of mandibular primary central and lateral incisor.

Fused primary or permanent teeth can be at increased risk for caries formation due to the presence of deep buccal and lingual grooves that occur at the site of fusion. These sites are difficult to clean and consequently require additional interventions. Fissure sealants may be applied to prevent caries development in the grooves and restorative treatment, such as composite resin restorations, should be considered when caries develops at these sites. If there is pulpal involvement due to a caries etiology, the fused tooth can present an endodontic challenge and the approach should be the same as for a multi-rooted tooth [92]. Fused permanent teeth can also be an esthetic concern, and dentists should take on an interdisciplinary approach in such instances.

\section{Gemination}

Gemination is defined as a failed attempt at division of a single tooth germ by invagination during the proliferation stage of tooth development, resulting in a tooth with an incompletely separated crown, a singular root, and single root canal [89]. While the overall etiology of germination remains unclear, contributing factors that have been proposed include genetic predisposition, trauma to the primary dentition, nutritional deficiencies, endocrine disturbances, systemic diseases, ionizing radiation, and drug toxicity It is suggested that these potential causative factors interrupt molecular signaling pathways involved with tooth germ development such as Wingless Int-1 (Wnt-1), Msh homeobox 1 and 2 (MSX-1 and MSX-2), tumor necrosis factor (TNF), bone morphogenetic protein (BMP), and fibroblast growth factor (FGF) to cause gemination or fusion [93].

The clinical features of gemination include the bifid appearance of the crown of the affected tooth. The crown size may appear larger than normal with a shallow or deep groove (on the buccal and/or lingual surfaces) that extends inciso-gingivally. Gemination is typically characterized by an otherwise normal count of total number of teeth in the affected arch. Radiographically, the practitioner should discern gemination from the presentation of a single root with a single canal and pulp chamber. Gemination has a higher prevalence in the primary dentition compared to permanent teeth (where it is rare). It occurs most often in the maxillary anterior region and has an equal sex predilection [93].

Similar to fusion, geminated teeth are also at increased risk for caries formation due to the presence of deep buccal and lingual grooves (Figure 14). Similar treatment options should be considered such as placement of fissure sealants to prevent caries development and composite resin restorations if caries develops in the grooves.

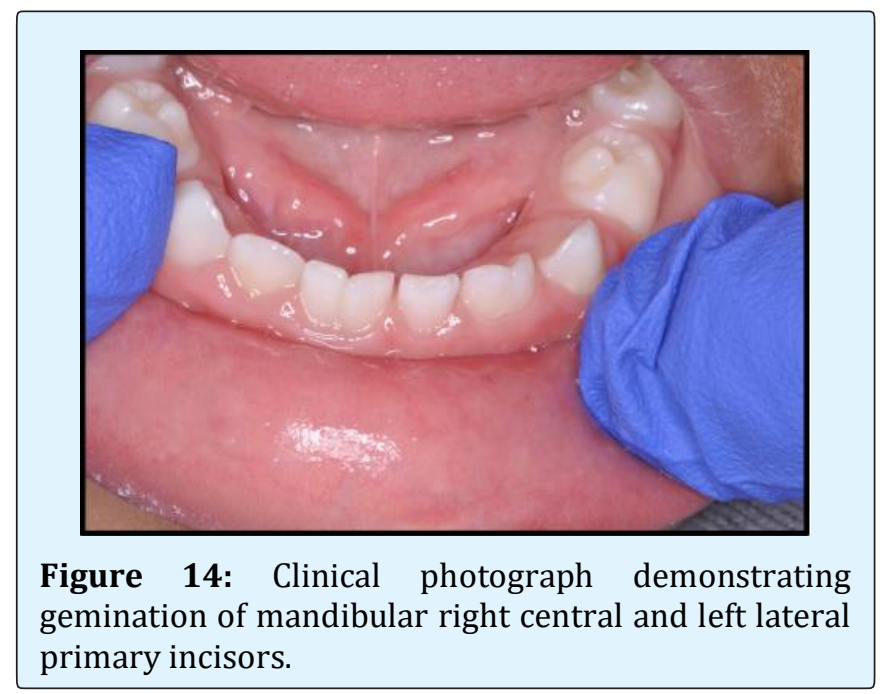

\section{Anomalies of Enamel and Dentin}

\section{Amelogenesis Imperfecta}

Enamel is the hardest tissue in the human body consisting of more than $90 \%$ mineral and less than $2 \%$ organic matrix and water. Amelogenesis imperfecta (AI) 
refers to a heterogeneous group of conditions with variable clinical manifestations that result from a lack of normal enamel formation. In addition to affecting the morphological appearance of enamel, it is also characterized by compositional changes in enamel [94]. AI can be autosomal dominant or sex-linked and affects both primary and permanent dentition. The prevalence ranges from 1:700 (95) to 1:14000 [95] depending on the population studied. Formation of enamel by ameloblasts takes place through the interactions of various organic matrix molecules such as amelogenin (AMELX), ameloblastin (AMBN), enamelin (ENAM), dentin sialophosprotein (DSPP), tuftelin (TUFT1), Kallikrein (KLK4) and matrix metalloproteinase 20 or enamelysin (MMP20). Various mutations in proteins such as amelogenin (AMELX), enamelin (ENAM), Kallikrein (KLK4), enamelysin (MMP20) and FAM83H are associated with development of AI [96].

There are various classification systems for AI (Figure 15). The most widely accepted classification includes 4 types of AI: hypoplastic, hypomaturation, hypocalcified, and hypomaturation-hypoplastic with taurodontism (associated with tricho-dento-osseous syndrome) [96]. AI can be also classified based on the mode of inheritance; however phenotypic heterogeneity can make this classification challenging.

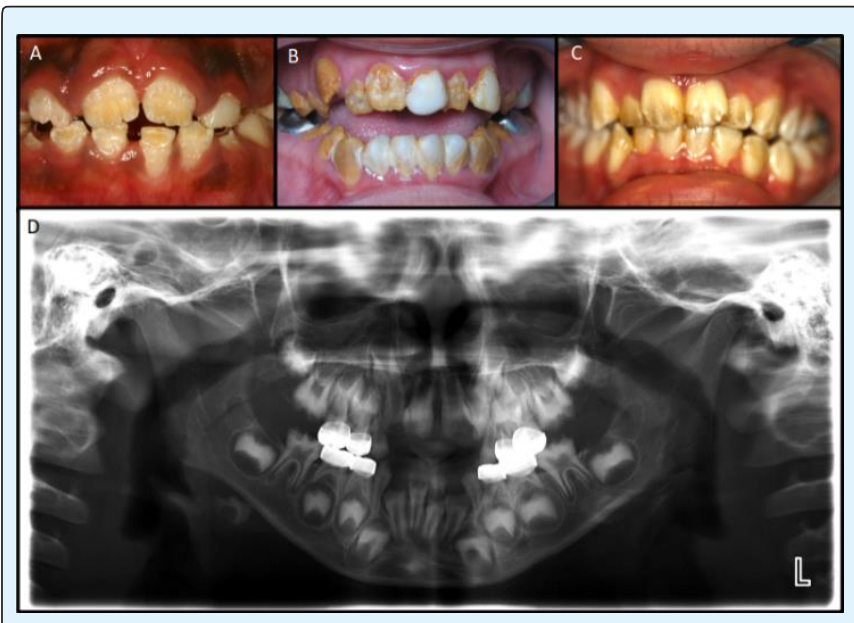

Figure 15: Clinical photographs demonstrating Amelogenesis Imperfecta (AI) types: hypocalcified (A), hypomineralized (B) and hypomaturation (C) with panoramic radiograph (D) demonstrating no discernable radiodensity of enamel.

Clinical findings in AI include discolored, soft, and sensitive enamel. AI can be associated with accelerated tooth eruption, caries susceptibility of the affected dentition, excessive calculus deposition, and gingival hyperplasia. Teeth affected with AI can demonstrate severe attrition [97]. Anterior open bites occur in patients presenting with the hypoplastic, hypocalcified, or hypomaturation types of AI. The differential diagnosis of AI includes severe dental fluorosis. However, unlike dental fluorosis, in AI all teeth are similarly affected. Due to the phenotypic variations associated with the condition, intra-oral radiographs to help identify the contrast between enamel and dentin should accompany meticulous clinical observations.

AI alone can be considered a syndrome and can present with other coexisting developmental dental anomalies such as impacted or ectopically erupting permanent teeth, pulp calcifications, and congenitally missing teeth. In isolated cases of AI, there are usually no associated systemic conditions. AI is also commonly associated with syndromes such as trico-dento-osseous syndrome. Due to the genetic etiology and potential for syndromic association, a careful collection of family history and pedigree analysis is recommended in suspected cases. Genetic analysis is not part of the routine care and diagnostic evaluation by the dental team. However, when support is available, genetic analysis can be a useful adjunctive tool for diagnosis and research. Once a diagnosis is made, genetic counseling for affected individuals and families should be provided.

Studies have demonstrated that patients affected by AI suffer significant negative psycho-social impacts and are usually concerned with their appearance and improving esthetics when seeking dental care [98]. During the primary dentition stage, transient treatment is provided while the permanent dentition is characterized by comprehensive care. Since young patients are often sensitive and anxious about treatment rendered, the majority of the dental treatment during the primary or mixed dentition stages has been performed under general anesthesia. Definitive treatment approaches includes fullcoverage restorations of the primary and permanent dentition. As the enamel is structurally and chemically weak, materials that require micro-mechanical bonding to enamel such as composite resin are not as successful as long-term restorative options. Resin modified glassionomer [99] and polyacid modified composite resins may be more beneficial due to their chemically adhesive properties to the underlying substrate [100]. Where malocclusion presents concurrently with AI, further orthodontic evaluation and treatment may be indicated. 
In addition to restorative and orthodontic management, preventive oral care is a critical aspect of the long-term management plan for affected patients. Professional application of sodium fluoride varnish can reduce caries risk in individuals affected by AI. Additionally, casein phosphopeptide and amorphous calcium phosphate (CPP-ACP) may be used to facilitate remineralization of hypomineralized tooth structure. Very few studies have reported improvement in aesthetics after application of CPP-ACP [101].

\section{Enamel Hypoplasia}

Enamel hypoplasia is defined as a disturbance in enamel matrix formation leading to pitting, grooving, and partial, or complete absence of enamel (Figure 16) [102]. Enamel hypoplasia has been associated with multiple and etiologic factors such as metabolic disorders, systemic infections, chemicals, or drug exposures (including excessive fluoride exposure) during development of the dentition $[103,104]$. Infectious diseases that have been implicated include congenital syphilis and viral infections such as measles, rubella, chicken pox, and cytomegalovirus (sew 2014). Children with celiac disease are also at risk for enamel hypoplasia due to the impaired absorption of minerals [105]. Traumatic dental injuries can be another etiologic factor due to local impacts to the primary dentition that secondarily affect the development of successor teeth [106]. Patients with syndromes such as DiGeorge syndrome and Kenny-Caffry syndrome can have enamel hypoplasia due to the associated systemic presentation of hypoparathyroidism with these conditions. Severe enamel hypoplasia is commonly associated with rickets occurring from vitamin D deficiency [107]. Moderate to severe forms of enamel hypoplasia can be seen in focal dermal hypoplasia or Goltz syndrome [108].

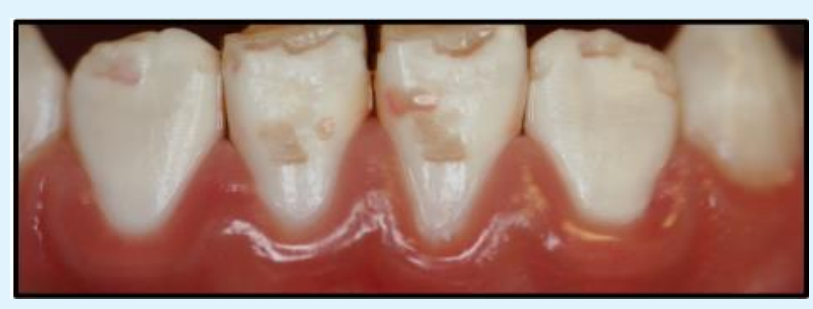

Figure 16: Clinical photograph showing localized enamel hypoplasia on facial surface of mandibular permanent central and lateral incisors.

Enamel hypoplasia can be clinically detected as opaque-chalky spots of enamel that have otherwise normal surface contours. Mineralization of the enamel can be due to disturbed enamel maturation. Based on the etiology and clinical manifestations, treatment can be vary for hypoplasia. In general, teeth affected with enamel hypoplasia may be sensitive and need a temporary sedative restoration to alleviate sensitivity. Generalized enamel hypoplasia may need more comprehensive management including full- coverage restorations such as stainless-steel crowns for primary dentition and more aesthetic crowns for the permanent dentition. Mild or localized enamel hypoplasia can be managed by microabrasion of affected enamel in combination with direct or indirect partial or complete composite veneers.

\section{Molar-Incisor Hypomineralization (MIH)}

MIH is defined as a condition in which areas of hypoplasia and hypomineralization develop on permanent molars and incisors (Figure 17) [109]. Childhood infectious diseases are one of the proposed etiologic factors for the development of MIH [104]. Additional etiologic factors such as malnutrition, respiratory and urinary infections, and use of antibiotics have been suspected. The prevalence rate for this anomaly ranges from 3.6 to $36 \%$ depending on the population studied [109]. Permanent first molars and incisors are the only affected teeth suggestive of the localized impact of etiologic factors during the time period from birth to 3 years of age [110].

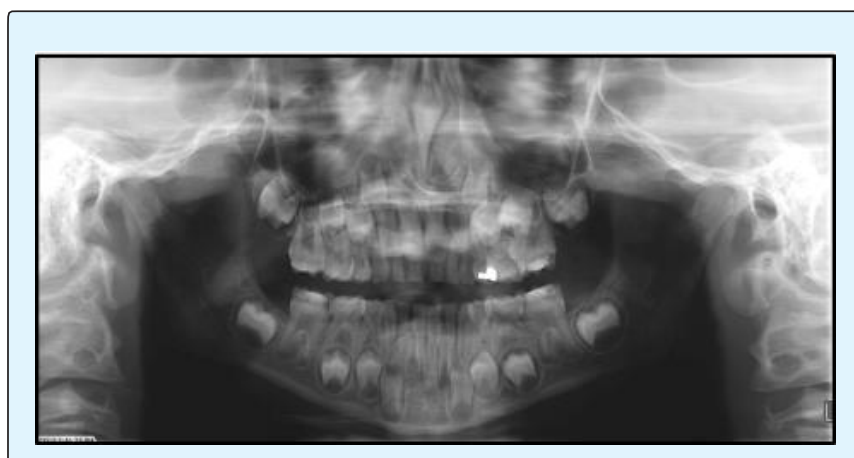

Figure 17: Panoramic radiograph showing molarincisor- hypomineralization (MIH) with no discernable radiodensity of enamel only on first permanent molars and permanent incisors' occlusal and incisal aspect respectively.

MIH affected patients may demonstrate post-eruptive loss of hypomineralized tooth structure [106] with tooth sensitivity as a common finding [111]. Clinically affected teeth can demonstrate yellow or brownish discolorations or opacities indicative of hypoplasia or 
hypomineralization [111]. MIH affected teeth are susceptible to caries and require restorative treatment. In such instances, the lack of adequate local anesthesia due to severe hypersensitivity can pose a significant barrier to the completion of planned dental treatments in a traditional clinical setting [111]. Some clinicians prefer to initially place sedative glass ionomer temporary fillings to alleviate sensitivity prior to final treatments that can range from restorations limited to affected surfaces or full-coverage restorations when multiple surfaces are involved. In severe cases, extractions are considered with an interdisciplinary approach that includes orthodontic (mesialization of second permanent molar) and/or prosthodontic management to maintain function and esthetics [112].

\section{Dentinogenesis Imperfecta (DI)}

Dentin is the second hardest tissue in the human body. It is composed of mineral (70\%), organic matrix (20\%), and water $(10 \%)$. The mineral phase is primarily hydroxyapatite whereas the organic phase is primarily formed by type I collagen and a small proportion of noncollagenous dentin phosphoprotein. Dentinogenesis imperfecta (DI) is a hereditary condition affecting dentin formation and/or mineralization. It can affect both primary and permanent dentition and may be present alone or in association with systemic disorders of bone such as osteogenesis imperfecta (OI). DI is also referred to as hereditary opalescent dentin or Capdepont dysplasia [113]. DI is classified into 3 categories:

a) Type I DI is usually associated with OI

b) Type II DI is usually present as a single entity

c) Type III DI is a rare variety characterized by shell like teeth with multiple pulp exposures in primary dentition

The incidence is reported to be 1 in 8000 [114]. The etiologic basis is a mutation of genes COL1A1 and COL1A2 (type I collagen). Mutations in the dentin sialophosphoprotein (DSPP) gene has also been reported to be associated with DI [115]. Associated syndromes include Ehlers-Danlos syndrome, Goldblatt syndrome, and osteodysplasia.

Affected teeth demonstrate discoloration ranging from grey to brown or yellow to violet with a classic translucent or opalescent hue (Figure 18). While caries incidence is low, clinically, excessive wear is a common finding that can result in pulpal pathology. Radiographically, teeth affected with DI demonstrate obliteration of pulpal spaces, short blunt roots, and bulbar crowns with cervical constrictions [113]. Genetic studies can be undertaken to identify associated mutations. The differential diagnoses include intrinsic discoloration such tetracycline staining, hypophosphatasia, cyclic neutropenia, regional odontodysplasia, and vitamin Ddependent rickets [116].

Based on the severity of the condition and affected dentition (primary or permanent) the aim of the treatment is to restore function and alleviate pain or infection. In the primary dentition, full-coverage, stainless-steel crowns are recommended. Pulp therapy for primary teeth with severe attrition may be indicated prior to restoring with stainless-steel crowns. In the permanent dentition, comprehensive care includes endodontic treatment and esthetic full-coverage restorations. In cases of severe attrition, onlays may be planned with possible over dentures to restore the patient's occlusion. In addition to restorative therapy, preventive management includes professional fluoride application and regular recall visits.

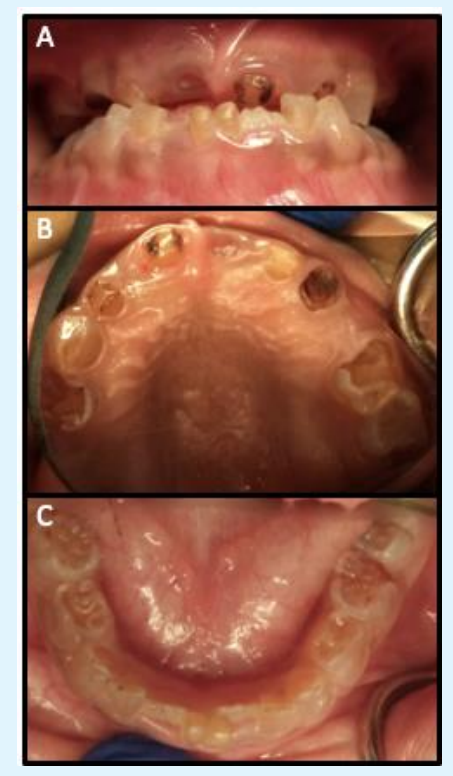

Figure 18: Clinical photographs: Anterior bite (A), maxillary (B) and mandibular occlusal (C) demonstrating translucent appearance of all primary and permanent teeth in a six-year old patient due to Dentinogenesis Imperfecta (DI).

\section{Dentin Dysplasia}

Dentin dysplasia (DD) is a rare anomaly characterized by normal crowns, short roots, and reduced pulp sizes in the primary and permanent dentition [117]. The 


\section{Open Access Journal of Dental Sciences}

classification includes type I DD that is clinically characterized by normal teeth with reduced pulps and associated periapical radiolucencies that can occur even with non-carious teeth.

Radiographically, there is evidence of short conical roots with apical constrictions, pulpal obliterations, and crescent shaped pulps (parallel to the cementoenamel junction) [118]. Type I DD may be associated with a DSPP gene mutation. In type II DD, the primary dentition may have the appearance of type I DD with unaffected permanent dentition. The radiographic appearance of type II DD includes a "thistle-tube" appearance of pulp chambers with pulp stones. Phenotypic variationsous are common in DD and clinical features may overlap with DI. However, the dental treatment is usually similar to that planned in cases of DI.

\section{Conclusion}

Developmental dental anomalies affecting the shape, number, position, and enamel or dentinal structures of the primary and permanent teeth can impact the overall form, function, and development of the jaws. While some developmental anomalies are mild deviations from normal with no indicated interventions, others require minor to comprehensive dental treatments using an interdisciplinary approach during the primary, mixed or permanent dentition stages. Clinicians should understand the various types of dental developmental anomalies, their pertinent clinical and radiographic features, associated systemic conditions or syndromes, and the available management approaches to better serve affected patients.

\section{References}

1. Tucker A, Sharpe $P$ (2004) The cutting-edge of mammalian development, how the embryo makes teeth. Nat Rev Genet 5(7): 499-508.

2. Gorlin's Syndromes of the Head and Neck. $5^{\text {th }}$ (Edn.), Oxford, New York: Oxford University Press; pp: 1520.

3. Cobourne MT (1999) The genetic control of early odontogenesis. Br J Orthod 26(1): 21-28.

4. MacKenzie A, Ferguson MW, Sharpe PT (1992) Expression patterns of the homeobox gene, Hox-8, in the mouse embryo suggest a role in specifying tooth initiation and shape. Dev Camb Engl 115(2): 403-420.
5. Jowett AK, Vainio S, Ferguson MW, Sharpe PT, Thesleff I (1993) Epithelial-mesenchymal interactions are required for msx 1 and msx 2 gene expression in the developing murine molar tooth. DevCambEngl 117(2): 461-470.

6. Shafer William G, Maynard K Hine, Barnet M Levy (2019) A Textbook of Oral Pathology. AbeBooks.

7. Hua F, He H, Ngan P, Bouzid W (2013) Prevalence of peg-shaped maxillary permanent lateral incisors: A meta-analysis. Am J Orthod Dentofacial Orthop 144(1): 97-109.

8. Howe BJ, Cooper ME, Vieira AR, Weinberg SM, Resick JM, et al. (2015) Spectrum of Dental Phenotypes in Nonsyndromic Orofacial Clefting. J Dent Res 94(7): 905-912.

9. Busenhart DM, Erb J, Rigakos G, Eliades T, Papageorgiou SN (2018) Adverse effects of chemotherapy on the teeth and surrounding tissues of children with cancer: A systematic review with meta-analysis. Oral Oncol 83: 64-72.

10. Kosowicz J, Rzymski K (1997) Abnormalities of tooth development in pituitary dwarfism. Oral Surg Oral Med Oral Pathol 44(6): 853-863.

11. Hertzberg J, Nakisbendi L, Needleman HL, Pober B (1994) Williams syndrome-oral presentation of 45 cases. Pediatr Dent 16(4): 262-267.

12. Matabuena Rodríguez M, Diz Dios $\mathrm{P}$, Cadarso-Suárez C, Diniz-Freitas M, Outumuro Rial M, et al. (2017) Reassessment of fluctuating dental asymmetry in Down syndrome. Sci Rep 7(1): 16679.

13. Parikh S, Gupta S (2012) Orodental findings in Hallermann-Streiff syndrome. Indian J Dent Res 23(1):124.

14. Laverty DP, Thomas MBM (2016) The restorative management of microdontia. Br Dent J 221(4): 160166.

15. Herrmann J, Pallister PD, Tiddy W, Opitz JM (1975) The KBG syndrome-a syndrome of short stature, characteristic facies, mental retardation, macrodontia and skeletal anomalies. Birth Defects Orig Artic Ser 11(5): 7-18. 
16. Alvesalo L, Osborne RH, Kari M (1975) The 47, XYY male, Y chromosome, and tooth size. Am J Hum Genet 27(1): 53-61.

17. Van Doorne L, Wackens G, De Maeseneer M, Deron P (1998) Otodental syndrome. A case report. Int J Oral Maxillofac Surg 27(2): 121-124.

18. Altug-Atac AT, Erdem D (2007) Prevalence and distribution of dental anomalies in orthodontic patients. Am J Orthod Dentofac Orthop 131(4): 510514.

19. Brook AH (1984) A unifying aetiological explanation for anomalies of human tooth number and size. Arch Oral Biol 29(5): 373-378.

20. Ooshima T, Ishida R, Mishima K, Sobue S (1996) The prevalence of developmental anomalies of teeth and their association with tooth size in the primary and permanent dentitions of 1650 Japanese children. Int J Paediatr Dent 6(2): 87-94.

21. Keith A (1913) Problems relating to the Teeth of the Earlier Forms of Prehistoric Man. Proc R Soc Med6 (Odontol Sect): 103-124.

22. Shaw JC (1928) Taurodont Teeth in South African Races. J Anat 62 (Pt 4): 476-498.

23. Dineshshankar J, Sivakumar M, Balasubramanium AM, Kesavan G, Karthikeyan M, et al. (2014) Taurodontism. J Pharm Bioallied Sci 6(5): 13-15.

24. Tsesis I, Shifman A, Kaufman AY (2003) Taurodontism: an endodontic challenge. Report of a case. J Endod 29(5): 353-355.

25. Lind V (1972) Short root anomaly. Scand J Dent Res 80(2): 85-93.

26. Puranik CP, Hill A, Henderson Jeffries K, Harrell SN, Taylor RW, et al. (2015) Characterization of short root anomaly in a Mexican cohort--hereditary idiopathic root malformation. Orthod Craniofac Res 18 (Suppl 1): 62-70.

27. Apajalahti S, Arte S, Pirinen S (1999) Short root anomaly in families and its association with other dental anomalies. Eur J Oral Sci 107(2): 97-101.

28. Ando S, Kiyokawa K, Nakashima T, Shibo K, Sanka Y (1967) Studies on the consecutive surgery of succedaneous and permanent dentition in Japanese children. 4. Behavior of short-rooted teeth in the upper bilateral central incisors. J Nihon UnivSch Dent 9(2): 67-82.

29. Apajalahti S, Hölttä P, Turtola L, Pirinen S (2002) Prevalence of short-root anomaly in healthy young adults. ActaOdontolScand 60(1): 56-59.

30. Lerman RL, Gold R (1977) Idiopathic short root anomaly. J Pedod 1(4): 327-333.

31. Edwards DM, Roberts GJ (1990) Short root anomaly. Br Dent J 169(9): 292-293.

32. Marques LS, Generoso R, Armond MC, Pazzini CA (2010) Short-root anomaly in an orthodontic patient. Am J Orthod Dentofac Orthop 138(3): 346-348.

33. Apajalahti $S$, Sorsa $T$, Ingman $T$ (2003) Matrix metalloproteinase $-2,-8,-9$, and -13 in gingival crevicular fluid of short root anomaly patients. Eur J Orthod 25(4): 365-369.

34. Fauzi NH, Ardini YD, Zainuddin Z, Lestari W (2018) A review on non-syndromic tooth agenesis associated with PAX9 mutations. Jpn Dent Sci Rev 54(1): 30-36.

35. Mallineni SK, Nuvvula S, Cheung ACH, Kunduru R (2014) A comprehensive review of the literature and data analysis on hypo-hyperdontia. J Oral Sci 56(4): 295-302.

36. Al-Ani AH, Antoun JS, Thomson WM, Merriman TR, Farella M (2017) Hypodontia: An Update on Its Etiology, Classification, and Clinical Management. BioMed Res Int 9378325.

37. Symons AL, Stritzel F, Stamation J (1993) Anomalies associated with hypodontia of the permanent lateral incisor and second premolar. J Clin Pediatr Dent 17(2): 109-111.

38. Puranik C, Redford-Badwal D (2017) Incontinentiapigmenti: A case report and literature review. J Pediatric Dentistry 5(2): 29-35.

39. Puranik CP, Katechia B (2019) Oral and dental findings in emanuel syndrome. Int J Paediatr Dent 29(5): 677-682.

40. Pippi R (2014) Odontomas and supernumerary teeth: is there a common origin? Int J Med Sci 11(12): 12821297. 


\section{Open Access Journal of Dental Sciences}

41. Fleming PS, Xavier GM, DiBiase AT, Cobourne MT (2010) Revisiting the supernumerary: the epidemiological and molecular basis of extra teeth. $\mathrm{Br}$ Dent J 208(1): 25-30.

42. Garvey MT, Barry HJ, Blake M (1999) Supernumerary teeth--an overview of classification, diagnosis and management. J Can Dent Assoc 65(11): 612-616.

43. Primosch RE (1981) Anterior supernumerary teeth-assessment and surgical intervention in children. Pediatr Dent 3(2): 204-215.

44. Primosch RE (1981) Anterior supernumerary teeth-assessment and surgical intervention in children. Pediatr Dent 3(2): 204-215.

45. Ata-Ali F, Ata-Ali J, Peñarrocha-Oltra D, PeñarrochaDiago M (2014) Prevalence, etiology, diagnosis, treatment and complications of supernumerary teeth. J ClinExp Dent 6(4): 414-418.

46. Lu X, Yu F, Liu J, Cai W, Zhao Y, et al. (2017) The epidemiology of supernumerary teeth and the associated molecular mechanism. Organogenesis 13(3): 71-82.

47. Nieminen $\mathrm{P}$, Morgan NV, Fenwick AL, Parmanen S, Veistinen L, et al. (2011) Inactivation of IL11 signaling causes craniosynostosis, delayed tooth eruption, and supernumerary teeth. Am J Hum Genet 89(1): 67-81.

48. Koch H, Schwartz O, Klausen B (1986) Indications for surgical removal of supernumerary teeth in the premaxilla. Int J Oral Maxillofac Surg 15(3): 273-281.

49. Shanmugha Devi G, Arangannal P, Muthu MS, Nirmal L (2002) Supernumerary teeth associated with primary and permanent teeth: a case report. J Indian Soc Pedod Prev Dent 20(3): 104-106.

50. Amarlal D, Muthu MS (2013) Supernumerary teeth: review of literature and decision support system. Indian J Dent Res 24(1): 117-122.

51. Sedano HO, Gorlin RJ (1969) Familial occurrence of mesiodens. Oral Surg Oral Med Oral Pathol 27(3): 360-361.

52. Russell KA, Folwarczna MA (2003) Mesiodens-diagnosis and management of a common supernumerary tooth. J Can Dent Assoc 69(6): 362366.
53. Seddon RP, Johnstone SC, Smith PB (1997) Mesiodentes in twins: a case report and a review of the literature. Int J Paediatr Dent 7(3): 177-184.

54. Tieu LD, Walker SL, Major MP, Flores-Mir C (2013) Management of ankylosed primary molars with premolar successors: a systematic review. J Am Dent Assoc 144(6): 602-611.

55. Mishra SK, Jindal MK, Singh RP, Stark TR, Hashmi GS (2010) Submerged and Impacted Primary Molars. Int J Clin Pediatr Dent 3(3): 211-213.

56. Arhakis A, Boutiou E (2016) Etiology, Diagnosis, Consequences and Treatment of Infraoccluded Primary Molars. Open Dent J 10: 714-719.

57. Walia T, Chandwani N (2019) Long-term management of an ankylosed young permanent incisor replanted within $2 \mathrm{~h}$ of avulsion: A case report with a 10-year follow-up. J Indian Soc Pedod Prev Dent 37(1): 99-106.

58. Hanisch M, Hanisch L, Kleinheinz J, Jung S (2018) Primary failure of eruption (PFE): a systematic review. Head Face Med 14(1): 5.

59. Decker E, Stellzig-Eisenhauer A, Fiebig BS, Rau C, Kress W, et al. (2008) PTHR1 loss-of-function mutations in familial, nonsyndromic primary failure of tooth eruption. Am J Hum Genet 83(6): 781-786.

60. Frazier-Bowers SA, Puranik CP, Mahaney MC (2010) The etiology of eruption disorders - further evidence of a "genetic paradigm." Semin Orthod. 16(3): 180185.

61. Bhuvaneswarri J, Chandrasekaran S (2018) Failure of Eruption of Permanent Tooth. Int J Appl Basic Med Res 8(3): 196-198.

62. Grippaudo C, Cafiero C, D’Apolito I, Ricci B, FrazierBowers SA (2018) Primary failure of eruption: Clinical and genetic findings in the mixed dentition. Angle Orthod 88(3): 275-282.

63. Ismail MQ, Lauridsen E, Andreasen JO, Hermann NV (2019) Ectopic eruption of the second premolar: an analysis of four different treatment approaches. Eur Arch Paediatr Dent.

64. Dabbagh B, Sigal MJ, Tompson BD, Titley K, Andrews P (2017) Ectopic Eruption of the Permanent Maxillary 


\section{Open Access Journal of Dental Sciences}

First Molar: Predictive Factors for Irreversible Outcome. Pediatr Dent 39(3): 215-218.

65. Hennessy J, Al-Awadhi EA, Dwyer LO, Leith R (2012) Treatment of ectopic first permanent molar teeth. Dent Update 39(9): 656-658, 660-661.

66. Barberia-Leache E, Suarez-Clúa MC, SaavedraOntiveros D (2005) Ectopic Eruption of the Maxillary First Permanent Molar: Characteristics and Occurrence in Growing Children. Angle Orthod 75(4): 610-615.

67. Hashemipour M-A, Tahmasbi-Arashlow M, FahimiHanzaei F (2013) Incidence of impacted mandibular and maxillary third molars: a radiographic study in a Southeast Iran population. Med Oral Patol Oral Cir Bucal 18(1): 140-145.

68. Mortazavi H, Baharvand M (2016) Jaw lesions associated with impacted tooth: A radiographic diagnostic guide. Imaging Sci Dent 46(3): 147-157.

69. Litsas G, Acar A (2011) A review of early displaced maxillary canines: etiology, diagnosis and interceptive treatment. Open Dent J 5: 39-47.

70. Becker A, Chaushu S (2015) Etiology of maxillary canine impaction: a review. Am J Orthod Dentofac Orthop 148(4): 557-567.

71. Ericson S, Kurol J (1988) Early treatment of palatally erupting maxillary canines by extraction of the primary canines. Eur J Orthod 10(1): 283-295.

72. Almasoud NN (2017) Extraction of primary canines for interceptive orthodontic treatment of palatally displaced permanent canines: A systematic review. Angle Orthod 87(6): 878-885.

73. Richardson G, Russell KA (2000) A review of impacted permanent maxillary cuspids--diagnosis and prevention. J Can Dent Assoc 66(9): 497-501.

74. Sherwood K (2013) Evidence-Based SurgicalOrthodontic Management of Impacted Teeth. Atlas Oral Maxillofac Surg Clin North Am 21(2): 199-210.

75. Massler M, Savara BS (1950) Natal and neonatal teeth; a review of 24 cases reported in the literature. J Pediatr 36(3): 349-359.
76. Spouge JD, Feasby WH (1966) Erupted teeth in the newborn. Oral Surg Oral Med Oral Pathol 22(2): 198208.

77. Cunha RF, Boer FA, Torriani DD, Frossard WT (2001) Natal and neonatal teeth: review of the literature. Pediatr Dent 23(2): 158-162.

78. Bjuggren G (1973) Premature eruption in the primary dentition-a clinical and radiological study. Sven Tandlak Tidskr J 66(4): 343-355.

79. Kates GA, Needleman HL, Holmes LB (1984) Natal and neonatal teeth: a clinical study. J Am Dent Assoc 109(3): 441-443.

80. Anderson RA (1982) Natal and neonatal teeth: histologic investigation of two black females. ASDC J Dent Child 49(4): 300-303.

81. Gladen BC, Taylor JS, Wu YC, Ragan NB, Rogan WJ, et al. (1990) Dermatological findings in children exposed transplacentally to heat-degraded polychlorinated biphenyls in Taiwan. Br J Dermatol 122(6): 799-808.

82. Alvarez MP, Crespi PV, Shanske AL (1993) Natal molars in Pfeiffer syndrome type 3: a case report. J Clin Pediatr Dent 18(1): 21-24.

83. Bodenhoff J, Gorlin RJ (1963) Natal and Neonatal Teeth: Folklore and Fact. Pediatrics 32: 1087-1093.

84. Jamani NA, Ardini YD, Harun NA (2018) Neonatal tooth with Riga-Fide disease affecting breastfeeding: a case report. Int Breastfeed J 13: 35.

85. Costacurta M, Maturo P, Docimo R (2012) Riga-Fede disease and neonatal teeth. Oral Implantol 5(1): 2630 .

86. van der Meij EH, de Vries TW, Eggink HF, de Visscher JG (2012) Traumatic lingual ulceration in a newborn: Riga-Fede disease. Ital J Pediatr 38: 20.

87. Duncan WK, Helpin ML (1987) Bilateral fusion and gemination: a literature analysis and case report. Oral Surg Oral Med Oral Pathol 64(1): 82-87.

88. Gellin ME (1984) The distribution of anomalies of primary anterior teeth and their effect on the permanent successors. Dent Clin North Am 28(1): 6980. 
89. Pereira AJ, Fidel RA, Fidel SR (2000) Maxillary lateral incisor with two root canals: fusion, gemination or dens invaginatus? Braz Dent J 11(2): 141-146.

90. Açıkel H, İbiş S, Sen Tunc E (2018) Primary Fused Teeth and Findings in Permanent Dentition. Med Princ Pract 27(2): 129-132.

91. Yuen SW, Chan JC, Wei SH (1987) Double primary teeth and their relationship with the permanent successors: a radiographic study of 376 cases. Pediatr Dent 9(1): 42-48.

92. Santos LM, Forte FDS, Rocha MJC (2003) Pulp therapy in a maxillary fused primary central incisor-report of a case. Int J Paediatr Dent 13(4): 274-278.

93. Hunasgi S, Koneru A, Manvikar V, Vanishree M, Amrutha R (2017) A Rare Case of Twinning Involving Primary Maxillary Lateral Incisor with Review of Literature. J Clin Diagn Res JCDR 11(2): ZD09-ZD11.

94. Aldred MJ, Savarirayan R, Crawford PJM (2003) Amelogenesis imperfecta: a classification and catalogue for the 21st century. Oral Dis 9(1): 19-23.

95. Bäckman B, Holm AK (1986) Amelogenesis imperfecta: prevalence and incidence in a northern Swedish county. Community Dent Oral Epidemiol 14(1): 43-47.

96. Crawford PJM, Aldred M, Bloch-Zupan A (2007) Amelogenesis imperfecta. Orphanet J Rare Dis 2: 17.

97. Poulsen S, Gjørup H, Haubek D, Haukali G, Hintze H, et al. (2008) Amelogenesis imperfecta - a systematic literature review of associated dental and oro-facial abnormalities and their impact on patients. Acta Odontol Scand 66(4): 193-199.

98. Aldred M, Crawford PJM, Savarirayan R, Savulescu J (2003) It's only teeth-are there limits to genetic testing? Clin Genet 63(5): 333-339.

99. Salanitri S, Seow WK (2013) Developmental enamel defects in the primary dentition: aetiology and clinical management. Aust Dent J 58(2): 133-140.

100. Chadwick BL, Evans DJP (2007) Restoration of class II cavities in primary molar teeth with conventional and resin modified glass ionomer cements: a systematic review of the literature. Eur Arch Paediatr Dent 8(1): 14-21.
101. Cochrane NJ, Reynolds EC (2012) Calcium phosphopeptides-mechanisms of action and evidence for clinical efficacy. Adv Dent Res 24(2): 41-47.

102. Via WF (1968) Enamel defects induced by trauma during tooth formation. Oral Surg Oral Med Oral Pathol 25(1): 49-54.

103. Kanchan T, Machado M, Rao A, Krishan K, Garg AK (2015) Enamel hypoplasia and its role in identification of individuals: A review of literature. Indian J Dent 6(2): 99-102.

104. Seow WK (2014) Developmental defects of enamel and dentine: challenges for basic science research and clinical management. Aust Dent J 59(Supply 1): 143154.

105. Majorana A, Bardellini E, Ravelli A, Plebani A, Polimeni A, et al. (2010) Implications of gluten exposure period, CD clinical forms, and HLA typing in the association between celiac disease and dental enamel defects in children. A case-control study. Int J Paediatr Dent 20(2): 119-124.

106. Seow WK, Humphrys C, Tudehope DI (1987) Increased prevalence of developmental dental defects in low birth-weight, prematurely born children: a controlled study. Pediatr Dent 9(3): 221-225.

107. Pettifor JM (2004) Nutritional rickets: deficiency of vitamin D, calcium, or both? Am J Clin Nutr 80(6): 1725-1729.

108. Wright JT, Puranik CP, Farrington F (2016) Oral phenotype and variation in focal dermal hypoplasia. Am J Med Genet C Semin Med Genet 172C(1): 52-58.

109. Weerheijm KL, Jälevik B, Alaluusua S (2001) Molarincisor hypomineralisation. Caries Res 35(5): 390391.

110. Vieira AR, Kup E (2016) On the Etiology of MolarIncisor Hypomineralization. Caries Res 50(2): 166169.

111. Jälevik B, Klingberg GA (2002) Dental treatment, dental fear and behaviour management problems in children with severe enamel hypomineralization of their permanent first molars. Int J Paediatr Dent 12(1): 24-32. 
112. Elhennawy K, Schwendicke F (2016) Managing molar-incisor hypomineralization: A systematic review. J Dent 55: 16-24.

113. Bhandari S, Pannu K (2008) Dentinogenesis imperfecta: a review and case report of a family over four generations. Indian J Dent Res 19(4): 357-361.

114. Shields ED, Bixler D, el-Kafrawy AM (1973) A proposed classification for heritable human dentine defects with a description of a new entity. Arch Oral Biol 18(4): 543-553.

115. MacDougall M, Simmons D, Luan X, Gu TT, DuPont BR (1997) Assignment of dentin sialophosphoprotein (DSPP) to the critical DGI2 locus on human chromosome 4 band q21.3 by in situ hybridization. Cytogenet Cell Genet 79(1-2): 121-122.

116. Barron MJ, McDonnell ST, Mackie I, Dixon MJ (2008) Hereditary dentine disorders: dentinogenesis imperfecta and dentine dysplasia. Orphanet J Rare Dis $3: 31$.

117. Kim JW, Simmer JP (2007) Hereditary dentin defects. J Dent Res 86(5): 392-399.

118. Fulari SG, Tambake DP (2013) Rootless teeth: Dentin dysplasia type I. Contemp Clin Dent 4(4): 520-522. 